\title{
Female Community Health Volunteers' (FCHVs) Involvement in Improving Maternal Health, Nepal
}

\section{Prakash Shahi}

Manavta, Research and Development (Sexual and Reproductive Health)

\section{Correspondence}

Email: pshahi1177@gmail.com

\begin{abstract}
Introduction: FCHV program has made a significant contribution to reducing maternal death in Nepal and is the foundation of Nepal's community-based primary health care system. Though the FCHV has had a huge positive impact, to continue the development of the programs for reducing maternal death this program needs to be properly monitored, strictly implement the guidelines and re-think the farewell package for FCHV.
\end{abstract}

Keywords: FCHV Program, Primary Health Care System

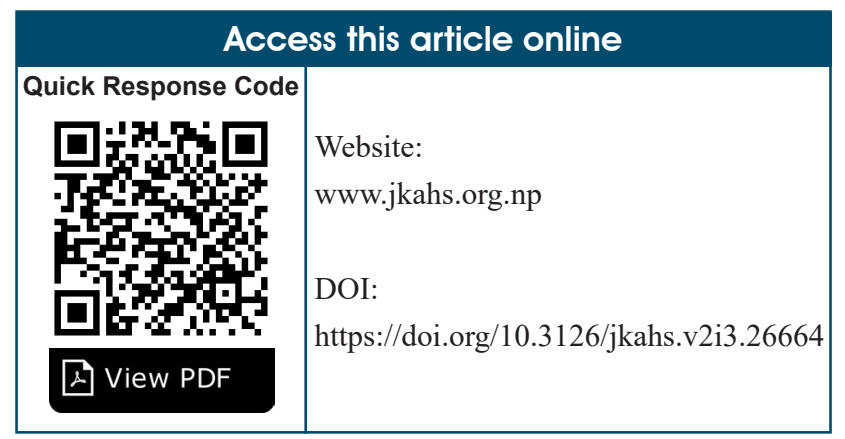

\begin{tabular}{|l|}
\multicolumn{1}{c|}{ Article Info. } \\
\hline How to cite this article? \\
\hline $\begin{array}{l}\text { Shahi P. Female Community Health Volunteers' (FCHVs) Involvement } \\
\text { in Improving Maternal Health, Nepal. Journal of Karnali Academy of } \\
\text { Health Sciences. 2019;2(3): } 250-252 .\end{array}$ \\
\hline Received: 17 Oct., Accepted: 27 Nov., Published: 11 Dec. 2019 \\
\hline Conflict of Interest: None, Source of Support: None \\
\hline
\end{tabular}

\section{INTRODUCTION}

Improving maternal health was one of the eight millennium development goals (MDGs) in 2000 and later included in SDG as a major agenda in 2015 which was adopted by the international community. ${ }^{1}$ In Nepal, the first elected democratic government developed Health Policy in 1991 and revised in 2014 which has identified safe motherhood as a priority program and institutionalized safe motherhood as a primary health care. ${ }^{2}$ In order to effectively address maternal and neonatal morbidity and mortality, the Family Health Division, Department of Health Services (DoHS) developed National Safe Motherhood Long Term Plan 2002- 2017 (revised in 2006) which aimed to establish basic and comprehensive emergency obstetric care services in all districts. To complement this plan, the National Policy on SBA (2006) was developed with the aim of increasing the percentage of births assisted by a skilled birth attendant (as internationally defined) to 60 percent by $2015 .^{3}$ Table 1 explains some historical shifts in maternal health policies and programs in Nepal.

\section{Table 1: Outline of historical shifts in maternal health policies and programs in Nepal}

\begin{tabular}{ll}
\hline Year & \multicolumn{1}{c}{ Events } \\
\hline 1987 & Global safe motherhood initiative launched \\
1988 & FCHV Program started \\
1991 & $\begin{array}{l}\text { Developed new health policy which identified same motherhood as a priority program } \\
\text { and institutionalized safe motherhood as primary health care } \\
2000\end{array}$ \\
\hline
\end{tabular}


Year

2002-2017

2005

2006

2006

2006-2017

2009

2009

2010-2015

2014

2015

\section{Events}

National Safe Motherhood Long Term Plan

Launched Maternity Incentive Scheme (MIS)

Revised MIS and renamed Safe Delivery Incentive Program (SDIP)

Developed national policy on skilled birth attendants

Safe motherhood and neonatal health long term plan

Revised SDIP and renamed Aama Surakshya Karyakram (ASK)

National free delivery policy

Nepal health sector program implementation plan II

National Health Policy Revised

Sustainable Development Goal (SDGs)
However, this paper is focused on Female Health Volunteer (FCHVs) which is recognized for having played a major role in reducing maternal, Neonatal mortality and general fertility in Nepal through community-based health programs., ${ }^{2,4,5}$

\section{Female Community Health Volunteer}

FCHVs are local women above 25 years of age who receive a basic 18 days training in various $\mathrm{PHC}$ topics including maternal and child health care services. ${ }^{5,6}$ FCHV program in Nepal was started in 1988 by the Ministry of Health and Population (MoHP) in order to improve community participation and to enhance the outreach of health services through local women working voluntarily. ${ }^{1,4,7}$ FCHV program is one of the seven programs components of family health division in Nepal which aims to support the achievement of national health goals through community involvement in public health activities. ${ }^{1,4}$

FCHV contribute extensively to the health and wellbeing of their communities, in particular to the women and children in rural areas of Nepal. Nearly 50,000 FCHVs are recruited and $97 \%$ of them are in the rural areas. $^{4,7}$

\section{Strength of FCHV}

FCHVs are highly respected and valued in the communities by involving themselves in the community activities. ${ }^{7}$ They are the cost effective way of reaching underserved and inaccessible population. ${ }^{6,8}$ Because FCHV services are almost always free, they are preferred by the disadvantaged group. ${ }^{1,3}$

FCHV are the foundation of Nepal's communitybased primary health care system and are the key referral links between the health services and communities. Additionally, FCHVs have made significant contributions to women's leadership and empowerment at the village development level. ${ }^{9}$

\section{Weakness of FCHV}

FCHVs are viewed increasingly as appropriate deliverers of health care and new tasks continue to be added. However, there is a risk that the program could be a victim of its own success. While new tasks can further raise FCHV visibility and social respect, these tasks may break with the definition of the volunteer role if they require attendance at specific times. The recent expansion of FCHV tasks in some districts to include being present during home births is one such example. While payment may threaten FCHVs' social status, an expectation that they carry out these tasks without payment is also unacceptable to FCHVs.

47 percent of FCHV have never been to school. FCHV who have never been to school tend not to perform equally well as who have been to school in terms of most services provided.10 More than 4 percent of FCHV are over 60 years old and still there is no appropriate exit policy for FCHV. ${ }^{1,10}$ 


\section{WAY FORWARD}

FCHV program has made significant contribution to reduce maternal death in Nepal and is foundation of Nepal's community-based primary health care system. Though the FCHV has had huge positive impact, to continue the development of the programs for reducing of maternal death this program needs to be properly monitored, strictly implement the guidelines and re-think the farewell package for FCHV.

\section{REFERENCES}

1. Shahi P, De Kok B, Tamang P. Inequity in the Utilization of Maternal-Health Care Services in South Asia: Nepal, India and Sri Lanka. International journal of health sciences and research. 2017 Jan 6;7(1 Jan2)

2. Ministry of Health and Population. Annual Report. Kathmandu Nepal :2019

3. Ministry of Health and Population. Annual Report. Kathmandu Nepal :2007

4. Era N. An analytical report on national survey of female community health volunteers of Nepal. USAID; 2008.

5. Panday S, Bissell P, Van Teijlingen E, Simkhada P. The contribution of female community health volunteers (FCHVs) to maternity care in Nepal: a qualitative study. BMC health services research. 2017 Dec;17(1):623.
6. Family Health Division (FHD). National female community health volunteer program strategy. Kathmandu: Family Health Division. Government of Nepal; 2010.

7. Bhutta ZA, Lassi ZS, Pariyo G, Huicho L. Global experience of community health workers for delivery of health related millennium development goals: a systematic review, country case studies, and recommendations for integration into national health systems. Global health workforce Alliance. 2010;1(249):61.

8. Walker DG, Jan S. How do we determine whether community health workers are costeffective? Some core methodological issues. Journal of community health. 2005 Jun 1;30(3):221-9.

9. Neupane D and Khanal V. A textbook of health service management in Nepal. Kathmandu. Vidyarthi pustak bhandar. Nepal. 2010.

10. ERA N. An Analytical Report on Female Community Health Volunteers of Selected Districts of Nepal. USAID; 2008. 